\title{
Quality and safety of bovine clones and their products
}

\author{
Y. Heyman ${ }^{1 \dagger}$, P. Chavatte-Palmer ${ }^{1}$, G. Fromentin ${ }^{2}$, V. Berthelot ${ }^{3}$, C. Jurie ${ }^{4}$, P. Bas ${ }^{3}$ \\ M. Dubarry ${ }^{2}$, J. P. Mialot ${ }^{1,5}$, D. Remy ${ }^{1,5}$, C. Richard ${ }^{6}$, L. Martignat ${ }^{7}$, X. Vignon $^{1}$ and \\ J. P. Renard ${ }^{1}$ \\ ${ }^{1}$ INRA, UMR 1198; ENVA; CNRS, FRE2857 Biologie du Développement et Reproduction, F-78352 Jouy en Josas, France; ${ }^{2}$ UMR 914 INA PG, F-75231 Paris, \\ France; ${ }^{3}$ UMR 791 INRA-INA PG, F-75231 Paris, France; ${ }^{4}$ INRA URH, F-63122 Theix, France; ${ }^{5}$ Ecole Nationale Vétérinaire Alfort, F-94704 Maisons-Alfort, France; \\ ${ }^{6}$ UCEA Bressonvilliers, F-91630 Leudeville, France; ${ }^{7}$ UMR IECM Ecole Nationale Vétérinaire, F-44307 Nantes, France
}

(Received 5 December 2006; Accepted 19 March 2007)

\begin{abstract}
A multidisciplinary research programme was developed to get a scientific expertise for the quality assessment of products obtained from cloned livestock. Thirty-seven bovine Holstein female clones of five different genotypes and their products were analysed in comparison with 38 control animals obtained by conventional artificial insemination and raised under the same conditions at the same experimental farm. Animal evaluation included over 150 criteria and more than 10000 measurements to check the physiological status and health over a 3-year period. All the parameters studied were in the normal range for age and breed, but some significant differences were detected between clone and control groups in terms of delayed onset of puberty in clones, higher neutrophil counts in haematology or lower biochemical plasma concentrations of gamma glutamyl transferase. Milk and meat analyses were conformable to expected values. We, however, found some differences in fatty acid (FA) composition of milk and muscle suggesting a possible deviation in lipid metabolism as assessed by higher delta-9 desaturase activity indexes in both milk and muscles from clones compared with controls. Repeated muscle biopsies in the semitendinosus muscle of the same animals demonstrated a higher oxidative activity in muscle of young clones (8 months of age) compared with controls, suggesting a delayed muscle maturation in clones. Nutritional evaluation of milk and meat using the rat feeding trials did not show any difference between clone and control products for food intake, growth rate, body composition of the rats, nor for possible allergenicity. Possible reactivation of bovine endogenous retroviruses (BERVs) was analysed and compared between normal and cloned cattle. As expected, these BERV sequences are not transcribed and no RNA was detected in the blood of clones, donor animals or controls; therefore, it may be assumed that the sanitary risk associated with BERV sequences is not higher in cattle derived from somatic nuclear transfer than in cattle born from conventional reproduction. Our results confirm that the quality and safety of products (milk and meat) from adult and clinically healthy cloned cattle is globally similar to normal animals. However, from a strictly biological point of view, the slightly delayed maturation we observed in the muscle of clones together with some marginal differences identified in FA composition of both muscle and milk, point to the need for more refined analysis to totally exclude any risks from the consumption of those products.
\end{abstract}

Keywords: cattle, meat safety, milk, somatic nuclear transfer

\section{Introduction}

The somatic cloning technology for farm animals is improving, especially in the bovine species where several hundred cloned cattle have been obtained world wide since 1998 when the first calves were born from somatic cell nuclear transfer (Cibelli et al., 1998; Vignon et al., 1998). Potential applications of this technology concern not only

${ }^{\dagger}$ E-mail: yvan.heyman@jouy.inra.fr biomedical research (Edwards et al., 2003; Wang and Zhou, 2003), but also agronomical use for livestock improvement (Bousquet and Blondin, 2004; Faber et al., 2004). Increasing information is becoming available on the characteristics of products from cloned cattle. There is, however, a great concern about their safety for human consumption. Risk assessment of products derived from cloned animals may be evaluated differently according to the geographical part of the world. For instance, the American Food and Drug Administration (USFDA) has proposed a methodology of 
two-pronged approach for evaluating the potential risks associated with the food products from animal clones (Rudenko et al., 2004) on the basis that food products originate from an animal which is a complex biological system and that, in any case, a healthy animal is likely to produce safe food. Therefore, milk or meat from clones should be analysed together with the health and physiology of the cloned animal. Recent publications have focused on the composition of meat and milk from cloned or noncloned animals (Walsh et al., 2003; Tian et al., 2005). All parameters studied were in the normal range of the previously recorded industry standards and no significant difference was observed between clone products issued from a limited number of animals and their controls. This approach is necessary but probably not sufficient to evaluate the risks associated with cloning and to answer uncertainties raised by this new technology. In Europe, it is considered that parameters other than the products themselves and the animals from which they originate, should also be taken into account for risk assessment. The process used to generate the animals (nuclear transfer technology) must be considered with regards to its possible impact on the genome (genetic risks) or on public perception (societal risks) (Renard and Chupin, 2004; Agence Française de Sécurité Sanitaire des Aliments, 2005).

Moreover, somatic cloning in cattle is associated with a high incidence of miscarriage and perinatal death compared with cattle born from conventional reproduction methods like artificial insemination (Al) (Heyman et al., 2002), but past the neonatal period most clones develop into adults with apparently normal physiology and capacity to produce offspring (Lanza et al., 2001; Chavatte-Palmer et al., 2004; Wells et al., 2004). Furthermore, somatic cloning generates animals that carry the nuclear genome of the donor cell. Indeed, during the nuclear transfer process, donor cells are fused to enucleated oocytes which contain different mitochondria, and remodelling of the donor nucleus is associated with epigenetic modifications that can alter genome expression. Therefore, somatic clones are not exactly as identical as natural monozygotic twins or calves resulting from embryo splitting.

Consequently, healthy looking clones may present subtle abnormalities related to the nuclear transfer techniques resulting in long-term effects. Epigenetic modifications at various levels of their genome may have taken place (Dean et al., 2001). These could lead to the onset of pathologies later in life as the result of very minor changes in chromatin structure and/or gene expression. Moreover, the altered foetal and placental growth that is well documented in bovine clones (Hill et al., 1999; Heyman et al., 2002; Constant et al., 2006) may also induce metabolic diseases in adulthood as a result of the foetal growth disturbance, as shown both in epidemiological studies in human and experimental work in animals (Barker and Clark, 1997; McEvoy et al., 2001; Gluckman and Hanson, 2004).

The purpose of the present experiment was to develop a multidisciplinary approach to establish a scientific expertise on the clones and their products as well as the possible incidence of nuclear remodelling on retroviral reactivation risk in the offspring. This evaluation was performed during a 3-year study on a large number of bovine female clones and their products to detect any possible difference between cloned and non-cloned control animals maintained under similar conditions in the same experimental farm at INRA, France.

\section{Material and methods}

\section{Animals}

A total of 75 bovine females (37 clones and 38 controls) were involved in the present 3-year study. All animals were born in the experimental farm at INRA between 1999 and 2003 and raised together under the very same conditions up to adulthood. Clones were derived from somatic nuclear transfer using skin fibroblasts from five different donor genotypes of the Holstein breed, according to the technique used in our laboratory (Vignon et al., 1998). Clone and control animals were paired by age for clinical, zootechnical and product evaluations. Whereas the clinical and zootechnical evaluations concerned most heifers, subsets of this group were involved in smaller comparative studies as described below.

This study was carried out as part of the research project on bovine cloning approved by the institutional ethical committee of INRA (COMEPRA). All the animal-related procedures were conducted by veterinarians and technicians by obtaining a licence for animal experimentation.

\section{Clinical study of the clones}

In this part of the study, 21 cloned heifers of four different genotypes and 18 control animals were examined repeatedly (every 2 months) from 4 to 24 months of age by the same veterinarians. Clinical observations were recorded and haematological, biochemical and endocrine factors were analysed from repeated blood and urine sampling (complete blood count $(C B C)$, total plasma proteins, albumin, fibrinogen, $\gamma$-glutamyl transferase (GGT), aspartate aminotransferase (ASAT), $\beta$-hydroxy butyrate $(\beta \mathrm{OH}$ butyrate), urea and creatinin). Moreover, plasma cortisol and urinary epinephrine and norepinephrin were measured in five clones and five controls from birth.

Until 100 days of age, food intake ratio was measured daily on a limited number of clones $(n=9)$ and control calves $(n=8)$. Thereafter, growth rates of all animals were evaluated by individual weighing every month.

Onset of puberty, cyclicity and fertility following Al were recorded. A group of 10 cloned and 11 control heifers were used. As mentioned previously, they were housed in the same barns, fed the same diet and weighed every month. Blood samples were taken by venipuncture from the caudal vein every 10 days between 8 and 14 months to detect cyclicity by radioimmunoassay (RIA) plasma progesterone analysis. Heat detection was carried out twice a day by 
visual observation. The age at puberty was evaluated by estimating first ovulation before progesterone rise and by heat detection. Cyclic cloned and control heifers were bred by $\mathrm{Al}$ at 15 to 16 months of age, following oestrus synchronisation using a progestagen implant (Crestar ${ }^{\circledR}$, Intervet, Angers, France). Frozen semen from the same bull was used throughout the study.

It has been hypothesised that bovine endogenous retrovirus (BERV) sequences could be activated as a result of the cloning process (Thibier, 2006). The presence of BERV sequences and copy number in the DNA of each animal was assessed by PCR using specific primers for BERV-L1, BERVL2 and BERV-E. The DNA was extracted from blood samples from 15 clones (three different genotypes) and 15 control cattle, as well as from the three cell donors. In a second step, RNA was also extracted and checked for presence or absence of transcripts of the three BERV sequences using RT-PCR.

\section{Milk analysis}

Milk production was monitored in 12 clones of three different genotypes and their contemporary controls. The total amount of milk produced in the first 305 days was used as the standard lactation period for dairy cattle. Milk analyses were performed monthly by the National Dairy Control Organisation using standardised methods for protein and fat contents and for cell counts.

Additional samples were obtained for specific experiments on fatty acid (FA) composition and for nutritional evaluation.

Fatty acid composition. FA composition of milk samples from five cloned (genotype A) and five control cows was analysed by gas chromatography after lipid extraction and FA methylation at days 80 and 180 of their first lactation (De Andrade and Schmidely, 2006). Stearoyl-CoA desaturase is a non-specific enzyme responsible for conversion of mainly saturated FA (C14:0, C16:0 and C18:0) into monounsaturated $F A$ via the introduction of a double bond at the delta-9-cis position of the saturated FA. An index of the activity of this enzyme can be calculated using the product/ (substrate+product) ratio (Malau-Aduli et al., 1997).

Nutritional studies on the rat model. The nutritional value of the milk was evaluated using a rat model. About $40 \mathrm{~kg}$ milk was collected from three clones of genotype $A$ at 80 days of lactation and pooled to prepare a single batch of yoghurt. Control yoghurt was made with the milk of three control cows at the same stage of lactation. Each batch was aliquoted and stored frozen until use. Two groups of eight Wistar rats (Harlan, France) weighing 220 to $240 \mathrm{~g}$ were first adapted to controlled conditions for light, temperature and to a normalised diet containing $14 \%$ total milk protein for 10 days. Thereafter, they received a normoproteic regimen based on control or clone yoghurt supplemented with milk proteins from control or cloned milk for a period of 3 weeks. Daily food intake and body weight were monitored. At the end of the experiment, blood was drawn from the femoral vein for glycaemia. The rats were sacrificed after pentobarbital anaesthesia and more blood was obtained by cardiac puncture for insulin assay and specific IgE/lgG antibodies against milk proteins. A necropsy was performed and organs weighed. Adipose tissue was carefully separated from the carcass and organs and weighed to assess adiposity.

\section{Muscle analysis}

The properties of the semitendinosus muscle from clone or control animals were compared in a longitudinal fashion using repeated muscle biopsies from the same animals. Muscle biopsies were obtained surgically under local anaesthesia from nine clones of a third genotype $(C)$ and eight controls at 8, 12, 18 and 24 months of age. Several aliquots were immediately snap frozen in liquid nitrogen and stored at $-80^{\circ} \mathrm{C}$ until analysis.

Fatty acid composition. Dry matter and FA contents were measured. FA composition was analysed by gas chromatography after lipid extraction and methylation according to Bas et al. (2005). Stearoyl-CoA desaturase indexes were calculated according to Malau-Aduli et al. (1997).

Metabolic characteristics of muscle. As metabolic muscle parameters are important for meat quality, lactate dehydrogenase (LDH) and isocitrate dehydrogenase (ICDH) activities were measured as described by Jurie et al. (1995) to assess glycolytic and oxidative metabolism, respectively. Values were compared between clones and controls at different ages using the $t$-test.

\section{Nutritional evaluation of meat}

The nutritional evaluation of the meat was performed using the rat model as for the milk evaluation. One 3-year-old cloned cow (genotype B) and one control cow were slaughtered at the experimental slaughterhouse at INRA. The same meat pieces were removed from the carcass and were used to prepare a single batch of minced meat from clone or control animals. Two groups of eight Wistar rats were fed ad libidum with this hyperproteic minced meat diet. Food intake, growth rate, carcass composition and blood samples after 3 weeks were evaluated as described for milk.

\section{Results}

Animal evaluation

Over 150 criteria were recorded in clones and controls to evaluate the physiological status and health over the timeperiod and more than 10000 measurements were made. 
Growth of clones up to 15 months of age was within normal values and was not different from controls. Daily weight gain between birth and 9 months of age was $0.87 \pm 0.10$ v. $0.81 \pm 0.10 \mathrm{~kg} /$ day, respectively, for clones $(n=13)$ and controls $(n=13)$. Total food intake needed from birth to a live weight of $100 \mathrm{~kg}$ was measured in nine clones and eight controls and was not statistically different between clones and controls $(2.15 \pm 0.19$ v. $2.17 \pm 0.20$, respectively), indicating that feeding efficiency is not modified in clones compared with control animals.

All clinical examinations and parameters recorded remained in the normal range for age-matched cattle, indicating that all animals were healthy (Smith, 1990). Significant differences, however, were observed, especially in the younger animals, as described in Table 1. For haematology, total red blood cells and packed cell volume were lower $(P<0.01)$ and neutrophil counts were higher $(P<0.01)$ in clones. In terms of biochemistry, plasma GGT and fibrinogen concentrations were higher in clones $(P<0.01)$ whereas $\beta 0 \mathrm{H}$ butyrate levels were lower $(P<0.01)$. Blood plasma cortisol and urinary adrenaline/ noradrenaline metabolites were not different between clones and controls.

The immune status was investigated by evaluating $T$ and $B$ lymphocyte subset population numbers in 17 clones and 17 controls in a resting immune status with no apparent infection and no inflammatory process. T cells and subsets, i.e. $\gamma / \delta$, memory $(C D 4+/ C D 45 R o+)$, helper (CD4), regulatory (CD25), cytotoxic (high CD8), NK cells (low CD8 and CD2+/CD3-) and B cells and polyspecific B1 (CD11b), monocytes $(\mathrm{CD} 11 \mathrm{C}+/ \mathrm{CD} 14+)$ and the overall expression of major histocompatibility complex types I and II (as a reflection of activation of the immune system) were measured by flow cytometry after specific marking of the cells. There was no difference between clones and controls. The cellular and antibody immune response to vaccination was tested at 8 to 9 months of age in six clones of three different genotypes and six controls using ovalbumin to evaluate the naïve immune response and a commercially available antirotavirus vaccine (Scourguard $3^{\mathrm{TM}}$, Pfizer, Paris, France). In a first experiment, the cellular response to two injections of ovalbumin was significantly lower in clones, but it was not different between clones and controls when a second booster was administered 3 months later. There was no difference either for antibody response or for cellular response to rotavirus vaccine.

Concerning sexual maturity, cloned heifers reached puberty significantly later $(419.3 \pm 42.5$ days $)$ and at heavier live body weight $(359.0 \pm 38.9 \mathrm{~kg}), P<0.05$, than control heifers $(356.5 \pm 50.5$ days and $303.0 \pm 22.3 \mathrm{~kg}$, respectively) (Table 2). After the first ovulation, however, the mean oestrus cycle length was similar in both groups $(20.9 \pm 0.9$ and $20.1 \pm 1.0$ days for clones and controls, respectively). Five out of eight females became pregnant at first $\mathrm{Al}$ in the clone group compared with $7 / 10$ in the control group and subsequently calved.

Cumulated data on calvings from clones show that 21 offspring were naturally delivered. Mean pregnancy duration and birth weight were within normal range limits for the breed (birth weight: $40.9 \mathrm{~kg}$ and gestation length: 280.1 days). Most calves (20/21, 95\%) survived after birth.

\section{Production \\ Lactation. Milk production was measured through 12 entire lactations of clone cows and the lactation curve was similar to that of 12 controls. All standard milk parameters (protein, fat, cell numbers, etc.) were repeatedly evaluated and remained within the normal range. The comparison of simultaneous standard 305-day lactations between clones and controls did not show any statistical difference between groups for total milk yield, fat and mean cell counts throughout lactation (Table 3). The mean protein content, however, was significantly higher $(P<0.01)$ in the clone group. This higher protein rate was mainly due to the three cloned cows of one genotype that had higher protein and lower milk production than the clones of other genotypes.}

Table 1 Major clinical, haematological and biochemical parameters (least-square mean \pm s.e.) in clones $(\mathrm{n}=21)$ and control $(\mathrm{n}=18)$ cattle from 4 to 24 months of age

\begin{tabular}{lcccc}
\hline \hline & \multicolumn{2}{c}{ Overall value for } & & \\
\cline { 2 - 3 } Parameters & Controls & Clones & & Normal range \\
\hline Red blood cells $\left(\times 10^{6} / \mathrm{l}\right)$ & $10.7 \pm 0.2$ & $10.1 \pm 0.2$ & 0.001 & $5-10$ \\
Packed cell volume $(\%)$ & $34.1 \pm 0.8$ & $29.8 \pm 0.9$ & 0.001 & $24-46$ \\
Neutrophils $\left(\times 10^{3} / \mu \mathrm{l}\right)$ & $3.0 \pm 0.2$ & $3.8 \pm 0.2$ & 0.001 & $0.6-4$ \\
Lymphocytes $\left(\times 10^{3} / \mu \mathrm{l}\right)$ & $4.5 \pm 0.2$ & $4.3 \pm 0.2$ & 0.32 & $2.5-7.5$ \\
Total proteins $(\mathrm{g} / \mathrm{l})$ & $66.1 \pm 1.1$ & $66.6 \pm 1.2$ & 0.74 & $67-75$ \\
Albumin $(\mathrm{g} / \mathrm{l})$ & $38.7 \pm 0.9$ & $36.9 \pm 1.0$ & 0.18 & $30-36$ \\
Fibrinogen $(\mathrm{g} / \mathrm{l})$ & $2.7 \pm 0.1$ & $3.0 \pm 0.1$ & 0.001 & $1-6$ \\
$\gamma$-glutamyl transferase $(\mathrm{IU} / \mathrm{l})$ & $17.8 \pm 0.7$ & $20.8 \pm 0.7$ & 0.003 & $2-35$ \\
Aspartate aminotransferase $(\mathrm{IU} / \mathrm{l})$ & $62.0 \pm 2.1$ & $66.4 \pm 2.3$ & 0.17 & $78-132$ \\
$\beta$ OH butyrate $(\mathrm{g} / \mathrm{l})$ & $1.63 \pm 0.04$ & $1.41 \pm 0.05$ & 0.001 & $<1.9$ \\
Urea (mmol/l) & $3.1 \pm 0.1$ & $3.0 \pm 0.1$ & 0.76 & $2.5-8.3$ \\
Creatinin $(\mu \mathrm{mol} / \mathrm{l})$ & $99.9 \pm 3.9$ & $88.8 \pm 4.5$ & 0.06 & $90-240$ \\
\hline \hline
\end{tabular}


Milk fatty acid composition. FA composition of milk samples from clone and control cows taken at two stages of the first lactation is shown in Figure 1. Clones had a higher proportion of $C 16: 1 C 9(P<0.10$ at day 80 and $P<0.001$ at day 180) and a lower proportion of $C 18: 0(P<0.05$ at day 80 and $P<0.001$ at day 180$), C 18: 1 t 11(P<0.09$ at day 80 and $P<0.01$ at day 180 , data not shown). Except for these FAs, no difference in FA composition was observed between the two groups of cows. Nevertheless, significantly

Table 2 Onset of puberty in clone and control Holstein heifers (mean \pm s.e.)

\begin{tabular}{lcc}
\hline \hline & \multicolumn{2}{c}{ Group } \\
\cline { 2 - 3 } & Clones & Controls \\
\hline $\begin{array}{l}\text { No. of heifers } \\
\text { Mean birth weight (kg) }\end{array}$ & $n=10$ & $n=11$ \\
$\begin{array}{l}\text { Mean age at puberty (day) } \\
\text { Mean body weight at }\end{array}$ & $419.3^{\mathrm{a}} \pm 3.6$ & $39.6^{\mathrm{b}} \pm 4.0$ \\
$\begin{array}{l}\text { puberty (kg) } \\
\text { Daily gain up to 15 months } \\
\text { (kg/day) }\end{array}$ & $359.0^{\mathrm{a}} \pm 38.9$ & $356.5^{\mathrm{b}} \pm 50.5$ \\
$\begin{array}{l}\text { Mean oestrous cycle length } \\
\text { before breeding (day) }\end{array}$ & $0.746 \pm 0.069$ & $0.779 \pm 0.085$ \\
\hline \hline
\end{tabular}

a,b Values within line with different superscript are significantly different at $P<0.05$ (Student $t$-test)

Table 3 Comparative milk production from clone and control cows

\begin{tabular}{|c|c|c|c|}
\hline & $\begin{array}{l}\text { Clone } \\
\text { cows }\end{array}$ & $\begin{array}{l}\text { Control } \\
\text { cows }\end{array}$ & $\begin{array}{c}t \text {-test } \\
(P \text { value })\end{array}$ \\
\hline $\begin{array}{l}\text { No. of controlled } \\
\text { lactations ( } 305 \text { days) }\end{array}$ & $n=12$ & $n=12$ & \\
\hline Mean production $(\mathrm{kg})$ & $7199 \pm 1590$ & $7502 \pm 576$ & 0.270 \\
\hline Fat $(\mathrm{g} / \mathrm{kg})$ & $40.6 \pm 3.9$ & $40.1 \pm 3.0$ & 0.377 \\
\hline Protein & $35.7 \pm 2.6$ & $33.0 \pm 1.7$ & 0.003 \\
\hline Cells $\left(\times 10^{3} / \mathrm{ml}\right)$ & $199 \pm 142$ & $173 \pm 122$ & 0.315 \\
\hline
\end{tabular}

higher stearoyl-CoA desaturase indexes were calculated in the milk from clone cows compared with that from control cows for the C16 $(P<0.16), C 18(P<0.02)$ and CLA (C18:2 $C 9, t 11$, conjugated linoleic acid, $P<0.01)$ indexes at day 80 and C14 $(P<0.02), \mathrm{C} 16(P<0.001), \mathrm{C} 18(P<0.001)$ and CLA $(P<0.001)$ indexes at day 180 (Figure $2 a)$.

\section{Muscle analysis}

Muscle characteristics. Muscle FA composition was analysed between 8 and 24 months. At 8 months, clones had a higher proportion of polyunsaturated fatty acids (PUFAs) (37.2 v. $28.4 \%, P<0.01$ ) and a lower proportion of saturated $(37.5$ v. $39.9 \%, P<0.01)$ and monounsaturated FA (18.7 v. 24.7, $P<0.02$ ) compared with controls (Table 4). This could be related to lower marbling in the meat of clones compared with that of controls. At 12, 18 and 24 months of age, differences were only observed for the saturated FA $(P<0.05)$ at 12 months and C18:0 $(P<0.10)$ at 24 months. The muscle stearoyl-CoA desaturase indexes were higher for the clones compared with controls for the C16 $(P<0.12)$ at 18 months and for $\mathrm{C} 14(P<0.11)$ and C16 $(P<0.02)$ at 24 months (Figure $2 b)$. The oxidative activity of the muscle, as measured through ICDH activity, was significantly higher in the muscle of clones than that of controls at 8 months of age $(1.16 \mathrm{v} .0 .55 \mu \mathrm{mol} / \mathrm{min}$ per $\mathrm{g}$, $P<0.001)$. This difference was equally observed at 12 months of age but in a less extent $(0.96$ v. $0.71 \mu \mathrm{mol} / \mathrm{min}$ per $g, P<0.07$ for clones and controls, respectively), but not afterwards (Figure 3). The glycolytic activity of the muscle, as measured through LDH activity, was not different in the muscle of clones than that of controls whatever the studied ages.

\section{Food safety}

Nutritional evaluation of milk and meat. The food intake and growth rate were similar for a 21-day period in the four different groups of experimental rats fed either a normoproteic diet based on yoghurt made from clone or
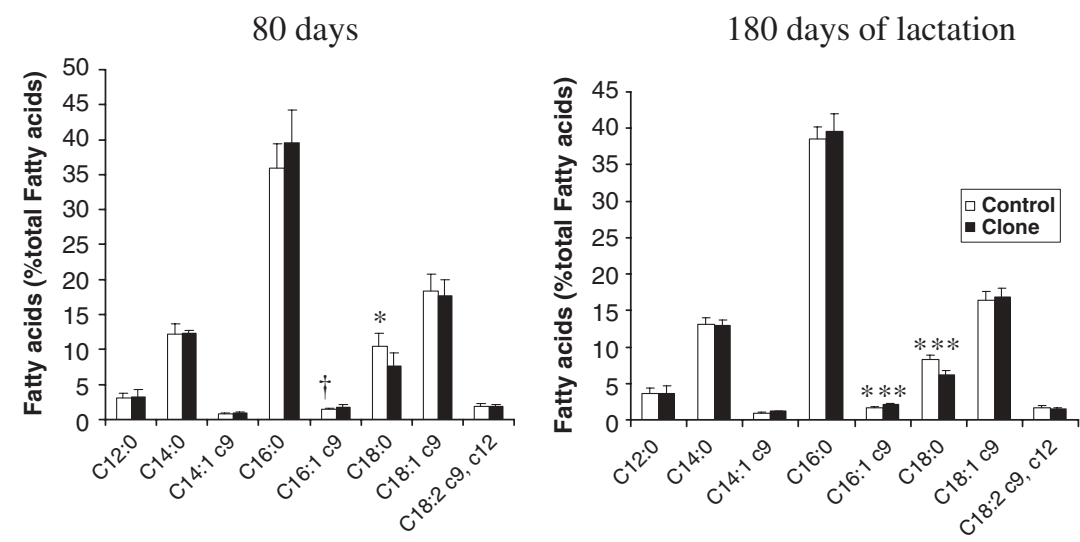

Figure 1 Fatty acid composition of milk from clone $(n=5)$ or control cows $(n=5)$ at two stages of lactation (days 80 and 180$)\left({ }^{\dagger} P<0.10\right.$; ${ }^{*} P<0.05$; $* \star * P<0.001)$. 
Heyman, Chavatte-Palmer, Fromentin, Berthelot, Jurie, Bas, Dubarry, Mialot, Remy, Richard, Martignat, Vignon and Renard
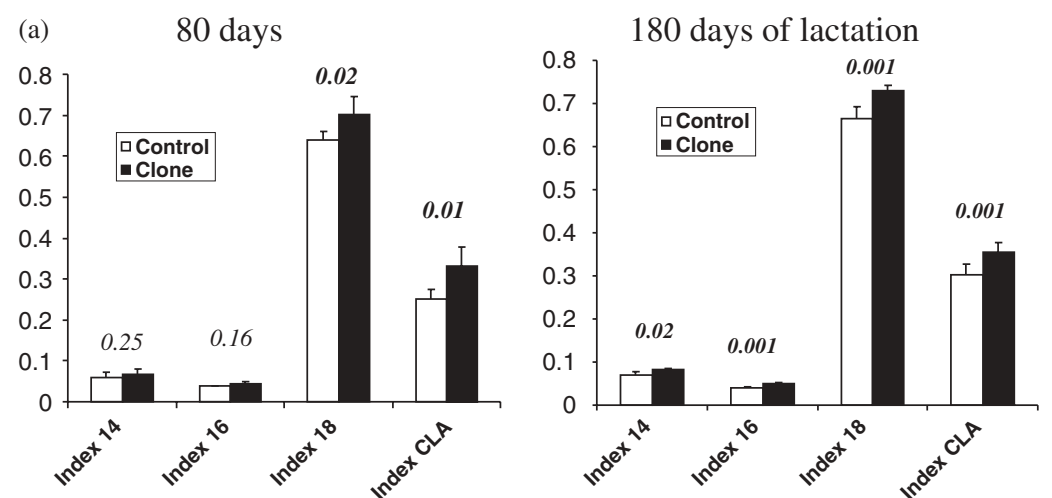

Index 14: C14:1 c9 / (C14:0 + C14:1 c9); Index 16: C16:1 c9 / (C16:0 + C16:1 c9)

Index 18: $\mathrm{C} 18: 1 \mathrm{c} 9 /(\mathrm{C} 18: 0+\mathrm{C} 18: 1 \mathrm{c} 9)$

Index CLA: C18:2 c9, t11 / (C18:1t11 + C18:1 c9, t11)
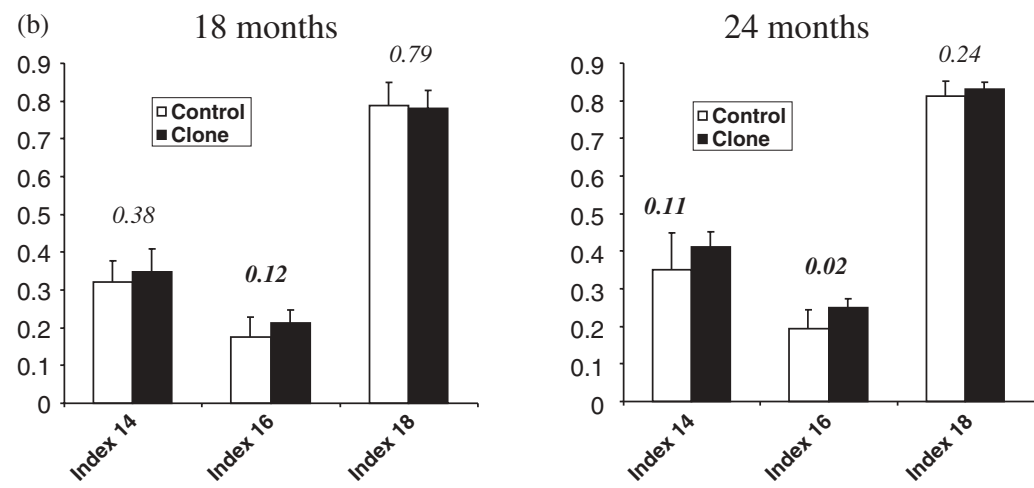

Index 14: C14:1 c9 / (C14:0 + C14:1 c9); Index 16: C16:1 c9 / (C16:0 + C16:1 c9)

Index 18: C18:1 c9 / (C18:0 + C18:1 c9)

Figure 2 Comparison of delta-9 desaturase indexes in (a) milk and (b) muscle between clone or control animals.

control milk, or an hyperproteic diet based on clone or control minced meat (Figure 4). The results of the organ weight measurements are shown in Table 5 . They did not reveal any significant difference between groups for any of the organs measured. The adiposity index (carcass weight/white adipose tissue) was similar between groups. Glycaemia was within the normal range and not different between groups $(1.05 \pm 0.04$ and $1.05 \pm 0.03 \mathrm{~g} / \mathrm{l}$ for groups fed control meat or clone meat, respectively).

None of the rats showed any allergenic response to the diet based on milk or meat from clones. A systematic analysis of plasma antibodies against yoghurt or meat was performed and specific lgE were not detected, indicating that there was no allergenic response. $\lg G, \lg A$ and $\lg M$ antibodies were detected but their concentration was not significantly different between groups.

Retroviral risk assessment. The three BERV sequences (BERV-1; BERV-2 and BERV-L) were detected in all the DNA analyses of blood samples from clones, controls and cell donor animals (Figure 5), but no transcripts for these sequences were detected by RT-PCR in the mRNA of these animals. These data confirm that these sequences are not reactivated after the nuclear transfer process and cannot generate retroviral particles, at least in the blood cells of cloned animals. Furthermore, we also observed that the nuclear transfer technology did not induce any modification in the number of copies for the three retroviral sequences examined.

\section{Discussion}

All parameters studied were within the normal range for the species and breed, indicating that clones can be classified as normal animals. In our conditions, the 3-year observation period did not reveal differences between a large number of clones and controls with regard to growth rate, food intake and clinical evaluation up to adulthood, confirming previous observations (Lanza et al., 2001; Heyman et al., 2004; Panarace et al., 2007). The data on lactation of clones are in agreement with previously published data on milk produced by a limited number of animals (Walsh et al., 2003; Tian et al., 2005). The absence of obvious deviation in the composition of the products, as recently reported for dairy products from clones (Laible et al., 2007), could be in favour of their use in the bovine industry despite concerns 
Evaluation of bovine clones and products

Table 4 FA composition of muscle biopsies from clone $(\mathrm{n}=9)$ or control $(\mathrm{n}=8)$ heifers at 8, 12, 18 and 24 months of age

\begin{tabular}{|c|c|c|c|c|c|c|c|c|c|c|c|c|c|c|c|c|}
\hline & \multicolumn{4}{|c|}{8 months } & \multicolumn{4}{|c|}{12 months } & \multicolumn{4}{|c|}{18 months } & \multicolumn{4}{|c|}{24 months } \\
\hline & Control & Clone & s.e. & $P$ & Control & Clone & s.e. & $P$ & Control & Clone & s.e. & $P$ & Control & Clone & s.e. & $P$ \\
\hline Dry matter (\%) & 29.9 & 29.1 & 0.5 & NS & 27.6 & 28.1 & 0.7 & NS & 31.9 & 33.0 & 0.4 & NS & 32.3 & 31.1 & 0.7 & NS \\
\hline \multicolumn{17}{|l|}{ FA ( $\%$ total FA) } \\
\hline C16:0 & 22.9 & 19.9 & 0.5 & 0.01 & 21.5 & 23.1 & 0.4 & 0.08 & 23.9 & 24.7 & 0.4 & NS & 24.6 & 23.6 & 0.5 & NS \\
\hline C18:0 & 14.0 & 14.7 & 0.3 & NS & 13.7 & 13.4 & 0.2 & NS & 9.4 & 9.5 & 0.4 & NS & 7.4 & 8.6 & 0.3 & 0.10 \\
\hline C18:1 c9 & 21.4 & 15.3 & 1.3 & 0.02 & 23.8 & 25.3 & 1.1 & NS & 34.0 & 36.2 & 1.3 & NS & 36.6 & 37.2 & 0.7 & NS \\
\hline C18:2 n-6 & 13.1 & 18.1 & 1.1 & 0.02 & 10.5 & 9.2 & 0.7 & NS & 5.4 & 4.4 & 0.6 & NS & 3.3 & 3.7 & 0.4 & NS \\
\hline C18:3 n-3 & 1.7 & 2.0 & 0.1 & 0.06 & 2.0 & 2.0 & 0.7 & NS & 1.1 & 0.9 & 0.1 & NS & 0.9 & 1.3 & 0.1 & NS \\
\hline $\mathrm{SFA}^{+}$ & 39.9 & 37.5 & 0.5 & 0.01 & 38.0 & 39.9 & 0.5 & 0.04 & 36.2 & 37.0 & 0.5 & NS & 35.1 & 35.0 & 0.5 & NS \\
\hline MUFA $^{\dagger}$ & 24.7 & 18.7 & 1.4 & 0.02 & 27.4 & 29.0 & 1.1 & NS & 39.1 & 40.7 & 1.4 & NS & 42.4 & 42.2 & 0.8 & NS \\
\hline PUFA $^{\dagger}$ & 28.4 & 37.2 & 1.9 & 0.01 & 27.0 & 23.2 & 1.6 & NS & 12.6 & 11.2 & 1.5 & NS & 9.7 & 11.9 & 1.3 & NS \\
\hline
\end{tabular}

FA = fatty acid composition; SFA = saturated fatty acid; MUFA = monounsaturated fatty acid; PUFA = polyunsaturated fatty acid.

${ }^{+} \mathrm{SFA}=\mathrm{C} 14: 0+\mathrm{C} 15: 0+\mathrm{C} 16: 0+\mathrm{C} 17: 0+\mathrm{C} 18: 0+\mathrm{C} 19: 0+\mathrm{C} 20: 0+\mathrm{C} 22: 0+\mathrm{C} 24: 0$. MUFA $=\mathrm{C} 16: 1+\mathrm{C} 17: 1+\sum \mathrm{C} 18: 1+\mathrm{C} 20: 1$.

PUFA $=\mathrm{C} 18: 2+\mathrm{C} 18: 3+\sum \mathrm{CLA}+\mathrm{C} 20: 3+\mathrm{C} 20: 4+\mathrm{C} 20: 5+\mathrm{C} 22: 4+\mathrm{C} 22: 5+\mathrm{C} 22: 6$.

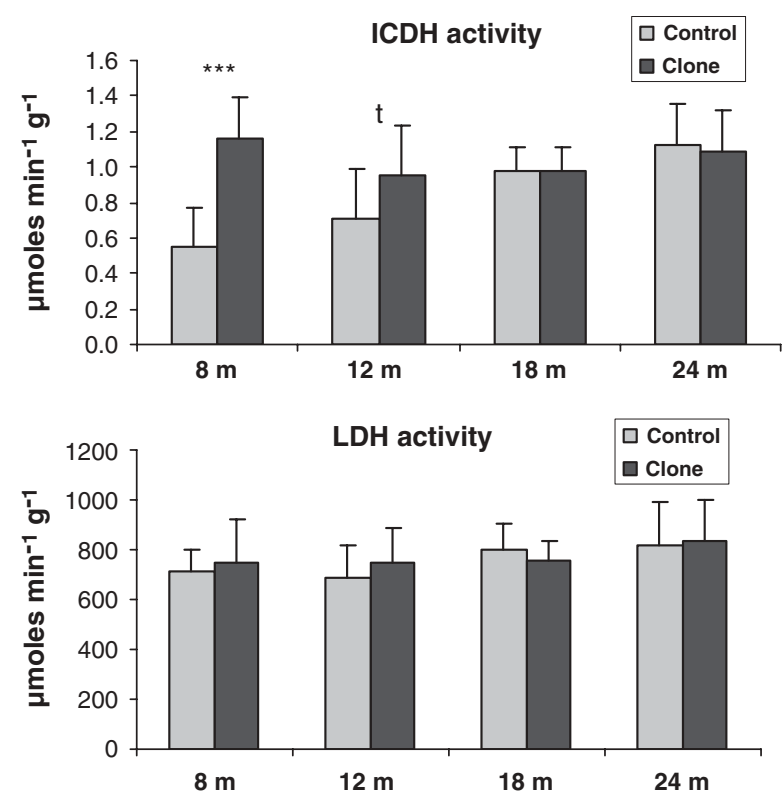

Figure 3 Metabolic enzyme activities: lactate dehydrogenase (LDH, glycolytic) and isocitrate dehydrogenase (ICDH, oxidative) in semitendinosus muscle from control $(n=8)$ or clone $(n=9)$ animals at $8,12,18$ and 24 months of age.

expressed by regulatory agencies or renowned scientists (Wilmut, 2002).

Nevertheless, during our study aimed to compare clones and control cattle under the same conditions, several significant differences were observed between clones and controls (haematological and biochemical parameters, muscle metabolism, milk and muscle FA composition, sexual maturation), which suggests that clones, while within the normal range of beef and dairy products, may not be totally similar to their age-matched controls for some parameters.

In particular, the repeated muscle biopsies demonstrated a higher oxidative activity (ICDH activity) in the semi-
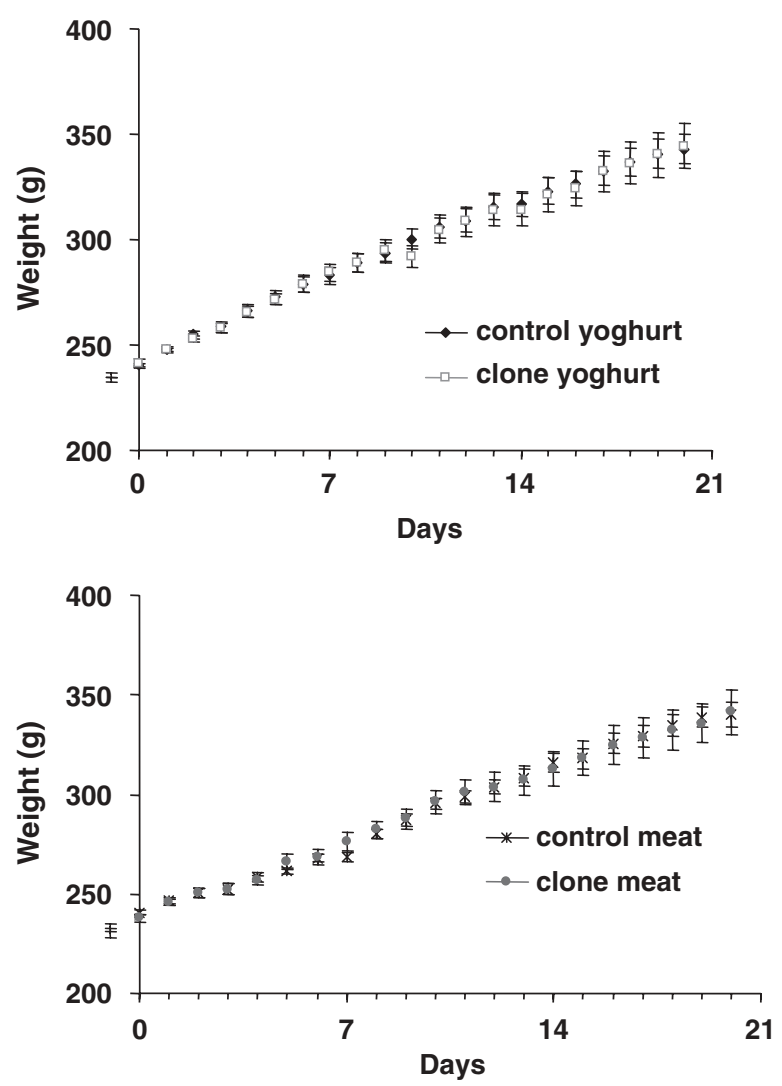

Figure 4 Evolution of body weight of rats fed with clone or control meat or milk.

tendinosus muscle of young cloned animals, whereas a glycolytic activity (LDH activity) was not affected, but the $L D H / I C D H$ ratio was significantly lower in clones at 8 months of age (data not shown). This suggests that the clones have a more oxidative muscular metabolism than controls, in particular at 8 and 12 months of age. This result indicates a delay in the metabolic differentiation of 


\begin{tabular}{lccrc}
\hline \hline & & \multicolumn{2}{c}{ Groups of experimental rats } \\
\cline { 2 - 5 } & Control yoghurt & Clone yoghurt & Control meat & Clone meat \\
\hline Mean body weight & $336.2 \pm 6.5$ & $344.0 \pm 10.5$ & $330.3 \pm 5.5$ & $330.5 \pm 10.6$ \\
Liver & $8.89 \pm 0.17$ & $8.65 \pm 0.48$ & $10.02 \pm 0.37$ & $9.48 \pm 0.60$ \\
Heart & $0.89 \pm 0.02$ & $0.90 \pm 0.04$ & $0.85 \pm 0.03$ & $0.86 \pm 0.04$ \\
Kidneys & $1.9 \pm 0.05$ & $1.9 \pm 0.07$ & $2.4 \pm 0.06$ & $2.4 \pm 0.12$ \\
White fat (total) & $29.5 \pm 3.0$ & $33.7 \pm 2.0$ & $28.5 \pm 1.1$ & $23.0 \pm 2.4$ \\
Epidydimis fat & $8.3 \pm 0.7$ & $9.4 \pm 0.5$ & $7.6 \pm 0.4$ & $6.7 \pm 0.7$ \\
Retroperitoneal fat & $9.6 \pm 1.0$ & $10.5 \pm 0.9$ & $9.3 \pm 0.4$ & $8.5 \pm 0.8$ \\
Subcutaneous & $11.5 \pm 1.4$ & $12.4 \pm 1.0$ & $11.4 \pm 0.6$ & $9.0 \pm 1.1$ \\
Carcass & $148.9 \pm 3.5$ & $144.3 \pm 5.2$ & $145.8 \pm 4.0$ & $71.2 \pm 4.1$ \\
Skin & $70.2 \pm 1.6$ & $74.3 \pm 4.6$ & & $68.0 \pm 2.0$ \\
\hline \hline
\end{tabular}

${ }^{+}$No significant difference was observed between groups $(P>0.05)$.

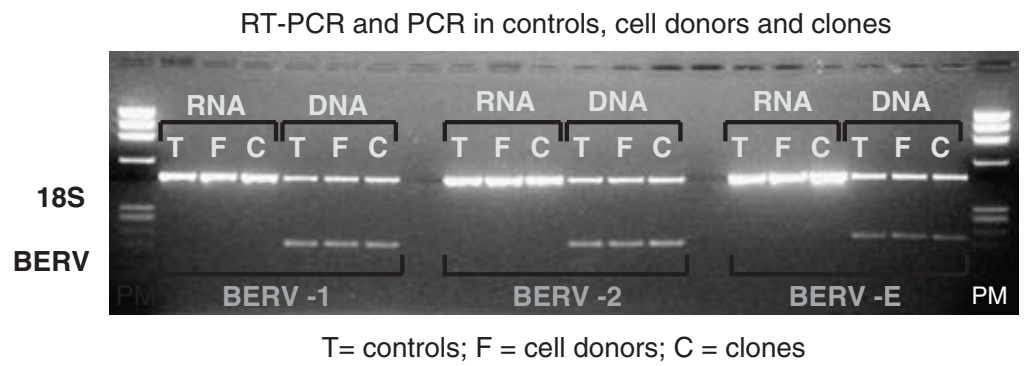

Figure 5 Evidence of DNA from three bovine endogenous retroviruses (BERV) and absence of their transcripts in the blood of clones, cell donor animals and controls.

cloned muscle. In fact, the same LDH/ICDH ratio, observed in clones at 8 months of age, was described in control animals aged 1 month (Jurie et al., 1995). Moreover, this delay was confirmed from cloned Holstein foetuses compared with control Charolais foetuses at 260 days post-conception (Picard et al., 2006).

Interestingly, in the present study we observed a delayed sexual maturation for the onset of puberty, suggesting that not only the muscle might be affected. Previous observations of delayed puberty in clones have already been reported by Enright et al. (2002) in a limited number of females from the same set of clones. Our data confirm this observation on clones from three different genotypes. Age at puberty is associated with body weight, but in our study the 2-month delay for the onset of puberty in clone females was not due to a difference in growth rate, as the daily gain up to 15 months of age was very similar in clones and controls. It remains to be determined if the observations on the evolution of clone muscle by the age of 8 to 12 months is linked to the observation of delayed puberty compared with control animals.

Several metabolic pathways contribute to the FA composition of products: uptake of plasma long-chain FAs, de novo synthesis of short- to medium-chain FA by the mammary gland or muscle tissue for FA and desaturation of 14 to 18 C-FA by the stearoyl-CoA desaturase. Only slight differences were observed in the FA composition of milk and muscle between the clone and control cows. In milk, differences were observed for palmitoic acid but not for palmitic acid and for stearic acid but not for oleic acid at both stages of lactation: these differences could be due to a change in the activity or quantity of the stearoyl-CoA desaturase, as in our design, the animals were kept in the same environment, fed the same diet and and their lactation had started around the same time. That was in agreement with the higher values of the stearoyl-CoA desaturase indexes 14,16, 18 and CLA in the clones compared with control cows. Consistently, higher values of stearoyl-CoA desaturase indexes in clones than in control were also observed for the muscle biopsies at 18 and 24 months of age even though the significance was less marked. These same differences observed in the delta- 9 desaturase of milk and muscle arising from two different families of clones could suggest that the same change in lipid metabolism of clones occurred. It was shown that stearoyl-CoA desaturase can be one of the causes of genotypic difference between and within breed (genetic variant) in FA composition of bovine muscle (Taniguchi et al., 2004a and b). However, in the present study, only two genotypes (families) were studied. More work is needed on other genotypes to confirm that these changes are present in all genotypes. Another hypothesis to explain the higher delta-9 desaturase index in clones could be related to rumen activity as trans-FA are generated by 
micro-organisms in the rumen but are desaturated in the mammary gland or in muscle. We cannot exclude a modification of the isomerisation process in the rumen of clones; meanwhile, they are fed the same regimen than controls. Further work is ongoing to analyse these difference between clones and controls at the molecular level by comparing gene expressions of this enzyme. In this situation, we can suppose that epigenetic modifications induced by the nuclear transfer technique may partly explain the different desaturase activity or the modified ruminal flora in clones.

The nutritional evaluation of milk and meat from clone and control cows using the rat model did not reveal any significant difference. Similar results were obtained in another study in Japan where rats were fed with chow containing 5\% meat powder (Takahashi and Ito, 2004). They observed no significant differences in general body condition, physiological functions, locomotion activity, nor in urine or blood analysis analyses between tested and control groups. In the present study, the rats were fed a whole unique diet of fresh minced meat and not dehydrated meat, without any detrimental effect. Longer trials, however, are required in order to confirm these results. In our study, the rats were fed with the different diets for a period of 3 weeks, which is a standard duration for food security analyses, especially since the rat is a very sensitive model. Indeed, during this period, any possible toxic effect associated with clone products should have been detected by the criteria used. Recently, a 14-week feeding test of meat and milk derived from cloned cattle has been conducted in the rat (Yamaguchi et al., 2007) and it was concluded that the physiological conditions of the rats were not affected.

In our study, the same milk samples have been used for both FA analysis and rat nutritional study (same female clone at day 80 of lactation). It is interesting to note that the significantly higher delta- 9 desaturase index observed in clone milk for a limited number of FAs had no effect on any of the parameters measured in rats fed with yoghurt from clone or control milk.

In conclusion, cloned animals, although apparently normal, are however significantly different from contemporary controls maintained in the same conditions, and we feel that more studies on clones and offspring of clones are necessary to evaluate the safety of their use for human consumption. Numerous aspects (Heyman et al., 2007) have to be taken into account to evaluate the value of meat and meat products derived from cloning as they have complex composition and we have to demonstrate both their safety and security but also to show that their nutritional value is equivalent to the traditional products of 'old-fashionproduced cattle'. This pilot study is a first step to develop further research on clones and offspring and increase trust of the consumer before possible use in the human food chain.

\section{Acknowledgements}

We thank all the staff of the experimental farm at Bressonvilliers and the staff of all the research laboratories involved for their assistance with this project. A special funding from INRA supported this multidisciplinary research programme.

\section{References}

Agence Française de Sécurité Sanitaire des Aliments 2005. Risks and benefits related to livestock cloning applications. Retrieved March 30, 2007, from http://www.afssa.fr/Object.asp? IdObj $=31874 \&$ Pge $=0 \& C C H=061121171926$ : 26:4\&cwSID = 893EE14535E0455EBB29E0AF38F42D25\&AID $=0$.

Barker DJP and Clark PM 1997. Fetal undernutrition and diseases in later life. Reviews in Reproduction 2, 105-112.

Bas P, Dahbi E, El-Aich A, Morand-Fehr P and Araba A 2005. Effects of feeding on fatty acid composition of muscles and adipose tissues in young goats raised in the Argan tree forest of Morocco. Meat Science 71, 317-326.

Bousquet D and Blondin P 2004. Potential uses of cloning in breeding schemes: dairy cattle. Cloning and Stem Cells 6, 190-197.

Chavatte-Palmer P, Remy D, Cordonnier N, Richard C, Issenman H, Laigre P, Heyman $Y$ and Mialot JP 2004. Health status of cloned cattle at different ages. Cloning and Stem Cells 6, 94-100.

Cibelli JB, Stice S, Golueke PJ, Kane JJ, Jerry J, Blackwell C, Ponce de Leon FA and Robl JL 1998. Cloned transgenic calves produced from non-quiescent fetal fibroblasts. Science 280, 1256-1258.

Constant F, Guillomot M, Heyman Y, Vignon X, Laigre P, Servely JL, Renard JP and Chavatte-Palmer P 2006. Large offspring or large placenta syndrome? Morphometric analysis of late gestation bovine placentomes from somatic nuclear transfer pregnancies complicated by hydroallantois. Biology of Reproduction 75, 122-130.

De Andrade PVD and Schmidely P 2006. Effect of duodenal infusion of trans10,cis12-CLA on milk performance and milk fatty acid profile in dairy goats fed high or low concentrate diet in combination of with rolled canola seed. Reproduction Nutrition Development 46, 31-48.

Dean W, Santos F, Stojkovic M, Zakhartchenko V, Walter J, Wolf E and Reik W 2001. Conservation of methylation reprogramming in mammalian development: aberrant reprogramming in cloned embryos. Proceedings of the National Academy of Sciences of the United States of America 98, 13734-13738.

Edwards JL, Schrick FN, McCracken MD, van Amstel SR, Hopkins FM, Welborn MG and Davies CJ 2003. Cloning adult farm animals: a review of the possibilities and problems associated with somatic cell nuclear transfer. American Journal of Reproductive Immunology 50, 113-123.

Enright BP, Taneja M, Schreiber D, Riesen J, Tian XC, Fortune JE and Yang X 2002. Reproductive characteristics of cloned heifers derived from adult somatic cells. Biology of Reproduction 66, 291-296.

Faber DC, Ferre LB, Metzger J, Robl JM and Kasinathan P 2004. Agro-economic impact of cattle cloning. Cloning and Stem Cells 6, 198-207.

Gluckman PD and Hanson MA 2004. Living in the past: evolution, development and patterns of disease. Science 305, 1733-1736.

Heyman $Y$, Chavatte-Palmer P, LeBourhis D, Camous S, Vignon X and Renard JP 2002. Frequency and occurrence of late-gestation losses from cattle cloned embryos. Biology of Reproduction 66, 6-13.

Heyman Y, Richard C, Rodriguez-Martinez H, Lazzari G, Chavatte-Palmer P, Vignon X and Galli C 2004. Zootechnical performance of cloned cattle and offspring: preliminary results. Cloning and Stem Cells 6, 111-120.

Heyman Y, Chavatte-Palmer P, Berthelot V, Fromentin G, Hocquette JF, Martignat $L$ and Renard JP 2007. Assessing the quality of products from cloned cattle: an integrative approach. Theriogenology 67, 134-141.

Hill JR, Roussel AJ, Cibelli JB, Edwards JF, Hooper NL, Miller MW, Thompson JA, Looney CR, Westhusin ME, Robl JM and Stice SL 1999. Clinical and pathological features of cloned transgenic calves and fetuses (13 case studies). Theriogenology 51, 1451-1465.

Jurie C, Robelin J, Picard B and Geay Y 1995. Post-natal changes in the biological characteristics of semitendinosus muscle in male Limousin cattle. Meat Science 41, 125-135.

Laible G, Brophy B, Knighton D and Wells D 2007. Compositional analysis of dairy products derived from clones and cloned transgenic cattle. Theriogenology 67, 166-177. 
Lanza RP, Cibelli JB, Faber D, Sweeney RW, Henderson B, Nevala W, West MD and Wettstein PJ 2001. Cloned cattle can be healthy and normal. Science 294, 1893-1894.

McEvoy TG, Robinson JJ and Sinclair KD 2001. Developmental consequences of embryo and cell manipulation in mice and farm animals. Reproduction $122,507-518$.

Malau-Aduli AEO, Siebert BD, Bottema CDK and Pitchford WS 1997. A comparison of the fatty acid composition of triacylglycerols in adipose tissue from Limousin and Jersey cattle. Australian Journal of Agricultural Research 48, 715-722.

Panarace M, Aguero JJ, Garrote M, Jauregui G, Segovia A, Cane A, Gutierrez J, Marfil M, Rigali F, Pugliese M, Young S, Lagioia J, Garnil C, Forte Pontes JE, Enero Junio JC, Mower S and Medina M 2007. How healthy are clones and their progeny: 5 years of field experience. Theriogenology 67, 142-151.

Picard C, Jurie C, Laigre P, Heyman Y, Vignon X, Cassar-Malek I, Hocquette JF and Chavatte-Palmer P 2006. Muscle development of cloned cattle foetuses. Meeting COST 925, Antalya, Turkey.

Renard JP and Chupin D 2004. Cloning and risk assessment: building-up a scientific expertise. Cloning and Stem Cells 6, 75-78.

Rudenko L, Matheson JC, Adams AL, Dubbin ES and Greenlees KJ 2004. Food consumption risks associated with animal clones: what should be investigated? Cloning and Stem Cells 6, 79-93.

Smith BP 1990. Large animal internal medicine. C.V. Mosby Company, St. Louis, MO

Takahashi S and Ito Y 2004. Evaluation of meat products from cloned cattle: biological and biochemical properties. Cloning and Stem Cells 6, 165-171.

Taniguchi M, Mannen H, Oyama K, Shimakura Y, Oka A, Watanabe H, Kojima T, Komatsu M, Harper GS and Tsuji S 2004. Differences in stearoyl-CoA desaturase mRNA levels between Japanese Black and Holstein cattle. Livestock Production Science 87, 215-220.

Taniguchi M, Utsugi T, Oyama K, Mannen H, Kobayashi M, Tanabe $\mathrm{Y}$ Ogino A and Tsuji S 2004. Genotype of stearoyl-CoA desaturase is associated with fatty acid composition in Japanese Black cattle. Mammalian Genome 15, 142-148.

Thibier M 2006. Biosecurity and the various types of embryos transferred. Reproduction Domestic Animals 41, 260-267.

Tian XC, Kubota C, Sakashita K, Izaike Y, Okano R, Tabara N, Curchoe C, Jacob L, Zhang Y, Smith S, Bormann C, Xu J, Sato M, Andrew S and Yang X 2005. Meat and milk compositions of bovine clones. Proceedings of the National Academy of Sciences of the United States of America 102, 6261-6266.

Vignon X, Chesné P, Lebourhis D, Fléchon JE, Heyman Y and Renard JP 1998. Developmental potential of bovine embryos reconstructed with enucleated matured oocytes fused with cultured somatic cells. Comptes Rendus de I'Académie des Sciences. Série 3, Sciences de la Vie 321, 735-745.

Walsh MK, Lucey JA, Govindasamy-Lucey S, Pace MM and Bishop MD 2003. Comparison of milk produced by cows cloned by nuclear transfer with milk from non-cloned cows. Cloning and Stem Cells 5, 213-219.

Wang B and Zhou J 2003. Specific genetic modifications of domestic animals by gene targeting and animal cloning. Reproductive Biology and Endocrinology 1, 103. doi:10.1186/1477-7827-1-103.

Wells DN, Forsyth JT, McMillan V and Oback B 2004. The health of somatic cell cloned cattle and their offspring. Cloning and Stem Cells 6, 101-110.

Wilmut I 2002. Are there any normal cloned mammals? Nature Medecine 8 , 215-216.

Yamaguchi M, Ito $Y$ and Takahashi S 2007. Fourteen-week feeding test of meat and milk derived from cloned cattle in the rat. Theriogenology 67, 152-165. 